\title{
Plazma D-dimer düzeyi ile erektil disfonksiyon arasındaki ilișkinin incelenmesi: Prospektif, olgu-kontrol çalıșması
}

\author{
Evaluation of the association between plasma D-dimer level and \\ erectile dysfunction: A prospective case-control study
}

Emre Karabay®, Serdar Duvar®

\section{öz}

AMAÇ: Bu çalışmanın amacı plazma D-dimer düzeyi ile erektil disfonksiyon (ED) arasında ilişki olup olmadığını araştırmaktır.

GEREC ve YÖNTEMLER: Ocak 2019 - Haziran 2019 tarihleri arasında Üroloji polikliniğine ED şikayetleri ile başvuran ve çalışmaya katılmak için gönüllü olan hastalara Uluslararası Erektil Fonksiyon İndeksi (IIEF-15) formu doldurularak, IIEF- Erektil fonksiyon (IIEF-EF) skoru <26 olan hastalar çalışmaya sıralı şekilde alındı. Kontrol grubu yaşa göre $+/-1$ eşleştirilerek gönüllü ve IIEF-EF skoru $\geq 26$ olan hastalardan oluşturuldu. Katılımciların demografik özellikleri ve laboratuvar bulguları kayıt altına alındı.

BULGULAR: Çalışmaya 37 ED (Grup 1) hastası ve 35 ED olmayan

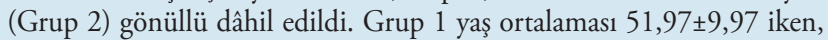

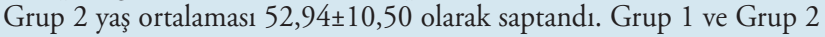
laboratuvar sonuçlarının değerlendirilmesinde; gruplar arasında plazma D-dimer düzeyleri açısından istatistiksel anlamlı farklılık saptanmazken $(\mathrm{p}=0,207)$, kontrol grubundaki plazma düşük yoğunluklu lipoprotein kolesterol (LDL-K) düzeylerinin hasta grubuna göre anlamlı olarak düşük olduğu gözlendi $(\mathrm{p}<0,05)$.

SONUÇ: Yüksek plazma D-dimer düzeylerinin koroner arter hastalarında uzun dönem arteryal ve venöz olayların prediktörü olduğu gösterilmiştir. Vasküler ED'nin koroner hastalıkların gelişiminde risk faktörlerinden biri olduğu bilinmektedir. Çalışmamızın ilk sonuçlarında plazma D-dimer düzeyi ile ED arasında anlamlı ilişki olmasa da geniş örneklem gruplu ileri çalışmaların yapılmasının bu alanda gerekli olduğunu düşünmekteyiz.

Anahtar Kelimeler: D-dimer, erektil disfonksiyon, IIEF

\section{Giriș}

Erektil disfonksiyon (ED) en sık görülen erkek cinsel fonksiyon bozukluklarından biri olup "bir erkeğin en az 6 ay süre ile seksüel ilişki için yeterli penis ereksiyonunu sağlama

Sağlık Bilimleri Üniversitesi, Haydarpaşa Numune SUAM, Üroloji Kliniği, İstanbul, Türkiye

Yazışma Adresi/ Correspondence:

Uzm. Dr. Emre Karabay

Haydarpaşa Numune SUAM,Üroloji Kliniği 34688 İstanbul, Türkiye

Tel: $\quad+905053858965$

E-mail: emrekarabay@gmail.com

Geliș/ Received: $\quad 14.06 .2020$

Kabul/ Accepted: $\quad 02.07 .2020$

\section{ABSTRACT}

OBJECTIVE: The aim of this study is to evaluate the relationship between levels of plasma D-dimer and erectile dysfunction (ED).

MATRERIAL and METHODS: International Index of Erectile Function-15 (IIEF-15) has been applied to patients referred to Urology outpatient clinic with the presence of ED. Patients with the score $<26$ of IIEF $-E F$ were included in the study. Controls consisted of subjects $+/-1$ age matched and with the IIEF-EF scores $\geq 26$. Demographic features and laboratory findings of the participants were recorded.

RESULTS: 37 patients with ED (Group 1) and 35 subjects without ED (Group 2) as the control group were included. The mean age was $51.97 \pm 9.97$ in Group 1 and $52.94 \pm 10.50$ in Group 2. No statistical significant difference was observed between Group 1 and Group 2 in terms of plasma D-dimer levels $(\mathrm{p}=0.207)$, while plasma LDLcholesterol levels was significantly lower in controls than in ED patients $(\mathrm{p}<0.05)$.

CONCLUSION: Plasma D-dimer levels were shown to be predictor in the development of long term arterial and venous events in coronary artery syndrome. Vascular ED is known to be one of the risk factors in the development of the coronary artery diseases. Although preliminary results of our study did not demonstrate a significant association between plasma D-dimer and ED presence, we believe that further studies with larger sample sizes are necessary.

Keywords: D-dimer, erectile dysfunction, IIEF ve/veya sürdürmede yetersizlik" olarak tanımlanmaktadır. [1] Ülkemizden yapılan bir prevelans çalışmasında $\geq 40$ yaş erkeklerin \%33'ünde ED saptandığı bildirilmiştir. ${ }^{[2]} \mathrm{ED}$ klasik olarak altta yatan patolojiye göre organik, psikojenik ya da nörojenik kökenli olmak üzere üç ana kategoride sınıflandırılmaktadır. Yapılan çalışmalar organik ED'nin çoğunlukla vasküler bir hastalık olduğunu ve endotelyal disfonksiyonun ED gelişmesindeki ana patolojik neden olduğunu desteklemektedir. ${ }^{[3]}$ Kardiyovasküler hastalık $(\mathrm{KVH})$ ve ED sıklıkla bir arada var olan iki durum olup her iki hastalık da diyabetes mellitus (DM), hipertansiyon, obezite ve dislipidemi gibi yaygın risk faktörlerini paylaşan sistemik vasküler hastalığın sonuçlarıdır. ${ }^{[4]}$ Sıklıkla bir arada görülmesinin yanı sıra ED'nin kardiyovasküler olay için 
bir prediktör olduğu gösterilmiş ve kardiyovasküler olay geçiren erkeklerde ED sıklığında artış olduğu bildirilmiştir. $^{[5,6]}$

Bir fibrin yıkım ürünü olan plazma D-dimer, akut ven trombozunu tespit etmek için değerli bir klinik testtir. Genel bir tromboz işareti olduğundan, bazal D-dimer konsantrasyonu ayrıca koroner kalp hastalığı ve venöz tromboembolizm de dahil olmak üzere gelecekteki KVH riskinin epidemiyolojik bir göstergesi olarak hizmet eder. ${ }^{[7]}$ Plazma D-dimer yüksekliği artmış olan hastalarda koroner arter hastalık (KAH) görülme sıklığının arttığı bildirilmiş, bu hasta grubunda periferal damarlarda da ateroskleroz düzeyinde artış olduğu gösterilmiştir. ${ }^{[8]}$ Ateroskleroz patogenezinde inflamasyon, oksidatif stres ve kontrolsüz hücre proliferasyonu da dahil olmak üzere tromboz gelişimi ile ortak birkaç moleküler yolak olduğu bilinmekte ve trombozun bir belirteci olarak plazma D-dimer düzeylerinin, bu patolojik yolaklardaki artan aktiviteyi yansıtıyor olabileceği düşünülmektedir. ${ }^{[0]}$

$\mathrm{Bu}$ çalışmanın amacı erkek hastalarda plazma D-dimer düzeyleri ile ED arasında ilişki olup olmadığını araştırmaktır.

\section{GEREÇ VE YÖNTEMLER}

\section{Çalıșma Popülasyonu}

Bu prospektif olgu-kontrol çalışması, Ocak 2019 - Haziran 2019 tarihleri arasında Sağlık Bilimleri Üniversitesi, Haydarpaşa Numune Eğitim ve Araştırma Hastanesi Üroloji Kliniği’ne ereksiyon yetmezliği şikayeti ile başvuran $18-75$ yaş arası 37 erkek hasta ve yaşa göre $+/-1$ olarak eşleştirilmiş 35 gönüllü erkek dahil edilerek toplam 72 erkek katılımcı ile gerçekleştirildi. Çalışmanın tüm aşamalarında Helsinki Bildirgesi ilkelerine uyuldu. Tüm hastalardan çalışmada kullanılmak üzere verilerinin kullanımına izin verdiğini belirten yazılı bilgilendirilmiş gönüllü onamı alındı.

Çalışmaya 18-75 yaş arası tek eşli, heteroseksüel, son altı aydır düzenli ilişkisi olan ve partnerinde gebelik durumu olmayan gönüllü erkekler dahil edildi. Bilinen böbrek yetmezliği, karaciğer sirozu, tiroid hastalı̆̆ı, geçirilmiş akut miyokart infarktüsü, nörolojik veya psikiyatrik hastalık, malignite, pelvik ve/veya perineal travma, benign prostat hiperplazisi, üretral cerrahi, hipospadias öyküsü olan ve düzenli cinsel ilişkisi olmayan hastalar çalışma dışı bırakıld. Ek olarak, $\alpha$-bloker, 5- $\alpha$ redüktaz inhibitörü (5-ARi), fosfodiesteraz tip-5 inhibitörü (PDE-5i), antidepresan ve antipsikotik ilaç kullanmakta olan hastalar da çalışma dışı bırakıldı.

\section{Katılımcıların değerlendirilmesi}

Deneyimli bir ürolog tarafından bütün katılımcıların yüz yüze görüşme ile cinsel ve tıbbi geçmişleri, yaşam tarzı faktörleri ve eşlik eden hastalıkları kayıt altına alındı. Standart bir seksüel anamnez formu hazırlanarak bütün katılımcıların demografik özellikleri, tıbbi ve cinsel öyküsü sözel olarak soruldu ve cevaplar standardize edilmiş seksüel anamnez formuna kaydedildi. Erektil ve cinsel fonksiyonların objektif bir şekilde değerlendirebilmesi için hastalara Uluslararası Erektil Fonksiyon İndeksi-15 [International Index of Erectile Function-15 (IIEF-15)] formu hakkında kısaca bilgi verildi ve formu cevaplamaları istendi. IIEF15 ile hastaların son 4 hafta içerisindeki cinsel fonksiyonları; erektil fonksiyon (6 soru) skorları kayıt edildi. IIEFEF skorundan elde edilen ED derecesine göre hastalar iki gruba ayrıldı; 0-25 aralığında skoru olan hastalar ED ve 26-30 arası skoru olan hastalar ED olmayan gruba alındı.

Katılımcıların sekonder cinsiyet özellikleri, testislerin k1vamı ve boyutu, penis deformiteleri, rektal dijital muayene sonuçları fizik muayene rapor formuna kaydedildi. Katılımcıların ağırlık ve boyları da kaydedilerek ve her katılımcı için vücut kitle indeksi (VKI) ağıllık/boy ${ }^{2}$ olarak $\left(\mathrm{kg} / \mathrm{m}^{2}\right)$ hesaplandı. Avrupa Üroloji kılavuzlarında önerildiği üzere bütün katılımcıların açlık kan şekeri (AKŞ) düzeyleri, lipid profillleri, total testesteron düzeyleri ve çalışma nedeniyle plazma D-dimer düzeyleri ölçüldü. ${ }^{[10]}$ Katılımcıların kan örnekleri gece açlığı sonrası sabah 08,00 ve 10,00 saatleri arasında antekubital venden elde edildi. D-dimer için sitratlı tüpe alınan kan örnekleri 4000 rpm'de 15 dakika santrifüj edildikten sonra enzim linked fluoresan assey (ELFA) metoduyla VIDAS cihazında çalışıldı.

\section{İstatistiksel Analiz}

Çalışmada elde edilen bulguların istatistiksel analizi NCSS (Number Cruncher Statistical System) 2007 (Kaysville, Utah, USA) programı ile yapıldı. Değişkenlerin normal dağılıma uygunluğu Shapiro-Wilk testi ile incelendi. Tanımlayıcı veriler, ortalama ( \pm standart sapma), medyan (minimum - maksimum) olarak ifade edildi. Dağıllım özelliklerine göre iki grup arasında fark bulunup bulunmadı$\breve{g} 1$ Student t-test ve Mann-Whitney U-testlerinden uygun olanı ile değerlendirildi. İstatistiksel alfa anlamlılık düzeyi iki yönlü $p$ değerinin 0,05 'ten küçük olması olarak kabul edildi.

\section{BULGULAR}

Çalışmaya yaş ortalaması $52,37 \pm 10,23$ yıl olan toplam 72 erkek olgu dâhil edildi. Çalışma popülasyonunun VKİ 
ölçümleri ortalama değeri $27,31 \pm 3,24 \mathrm{~kg} / \mathrm{m}^{2}$ olarak hesapland. Olguların 37 (\%51,3)'si ED grubunda (Grup 1) yer alırken, 35 (\%48,7)'i kontrol grubunda (Grup 2) yer aldı. Gruplara göre hipertansiyon varlığı, KAH ve DM varlığ açısından istatistiksel anlamlı fark saptanmazken $(p>0,05)$ Grup 1'de yer alan hastaların VKİ ortalama değerinin Grup 2'de yer alan hastalara göre istatistiksel olarak anlamlı şekilde daha yüksek olduğu izlendi $(p=0,018)$. Çalışma popülasyonunda bulunan hastaların demografik özellikleri Tablo 1'de özetlendi.

Gruplar arasında AKŞ ortanca değerleri ve total testesteron ortanca düzeyleri açısından istatistiksel olarak anlamlı farklılık saptanmadı $(p>0,05)$. Grup 1'de plazma D-dimer ortanca değeri [320 (140 - 1340)] Grup 2'deki plazma D-dimer ortanca değerinden [260 (120 - 680)] daha yüksek olmasına rağmen gruplar arasında istatistiksel olarak anlamlı farklılık görülmedi $(p>0,05)$. Grup 1'de yer alan hastaların ortalama düşük yoğunluklu lipoprotein kolesterol (LDL- K) değerinin Grup 2'de yer alan hastalara göre istatistiksel olarak anlamlı şekilde daha yüksek olduğu izlendi ( $p=0,021)$. Biyokimyasal parametrelerin her iki gruptaki ölçüm sonuçları ve iki grup arasındaki karşılaştırmalar Tablo 2'de özetlendi.

\section{TARTIȘMA}

$\mathrm{Bu}$ çalışmada ED tanısı alan erkek hastalarda plazma D-dimer ortanca değerleri kontrol grubuna göre yüksek bulunsa da gruplar arasında istatistiksel anlamlı fark saptanmamıştır. Bununla beraber ED tanısı alan erkek hastaların VKİ değerlerinin ve LDL-K düzeylerinin kontrol grubundaki kişilerden istatistiksel anlamlı olarak daha yüksek olduğu izlenmiştir.

Angelis ve ark. ${ }^{[11]}$, Tip 2 DM'li hastalarda ED ile endotelyal disfonksiyon arasındaki ilişkiyi araştırdıkları

Tablo 1. Çalışma popülasyonunun bazal demografik ve klinik özellikleri

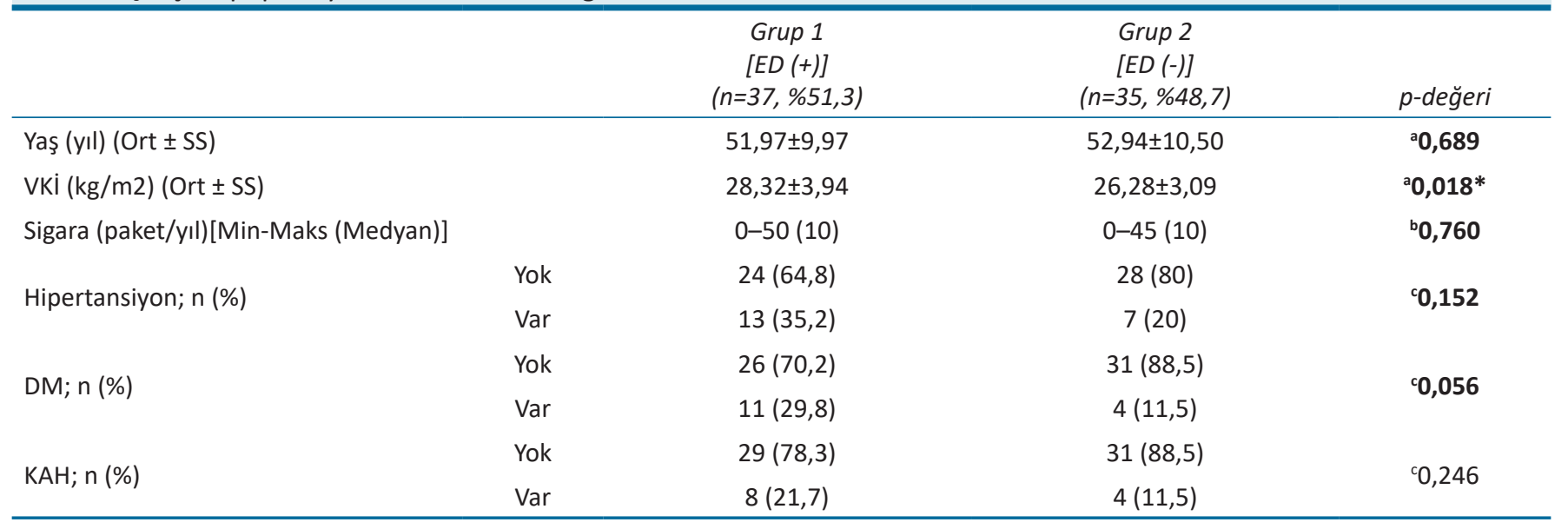

aStudent $t$ Test, ${ }^{b}$ Mann Whitney U Test, cPearson Chi-Square Test, ${ }^{*} \mathrm{p}<0,05$

Ort: Ortalama, SS: Standart sapma, Min: Minimum, Mak: Maksimum, VKi: Vücut kitle indeksi, DM: Diabetes mellitus KAH: Koroner arter hastalığı

Tablo 2. Gruplar arasında biyokimyasal parametrelerin karşılaştırılması

\begin{tabular}{|c|c|c|c|}
\hline & $\begin{array}{c}\text { Grup } 1 \\
{[E D(+)]} \\
(n=37, \% 51,3)\end{array}$ & $\begin{array}{c}\text { Grup } 2 \\
{[E D(-)]} \\
(n=35, \% 48,7)\end{array}$ & $p$-değeri \\
\hline AKŞ (mg/dL), [Min-Maks (Medyan)] & 49-223 (99) & $80-243(98)$ & b0,710 \\
\hline Trigliserid (ng/dL), [Min-Maks (Medyan)] & $50-467$ (117) & $66-567(135)$ & ${ }^{\mathrm{b}} \mathbf{0 , 1 3 3}$ \\
\hline Total Kolesterol (ng/dL) (Ort $\pm \mathrm{SS})$ & $187,76 \pm 47,24$ & $168,94 \pm 43,69$ & ${ }^{\mathrm{a}} 0,084$ \\
\hline HDL-Kolesterol (ng/dL) (Ort $\pm \mathrm{SS})$ & $40,84 \pm 10,21$ & $42,31 \pm 9,33$ & ${ }^{\mathrm{a}} \mathbf{0 , 5 2 5}$ \\
\hline LDL-Kolesterol (ng/dL) (Ort \pm SS) & $118,40 \pm 37,49$ & $95,74 \pm 43,02$ & ${ }^{\mathrm{a}} 0,021 *$ \\
\hline VLDL-Kolesterol (ng/dL), [Min-Maks (Medyan)] & 10-97 (24) & $14-109(27)$ & '⿳0,177 \\
\hline Total Testosteron (ng/dL), [Min-Maks (Medyan)] & $1,56-9,77(4,64)$ & $1,42-9,55(4,66)$ & b0,632 \\
\hline $\begin{array}{l}\text { D-Dimer (ng/mL) } \\
\text { [Min-Maks (Medyan)] }\end{array}$ & $140-1340(320)$ & $120-680(260)$ & '0,207 \\
\hline
\end{tabular}

aStudent t Test, ' Mann-Whitney U Test, ${ }^{*} \mathrm{p}<0,05$

Ort: Ortalama, SS: Standart sapma, Min: Minimum, Mak: Maksimum, AKŞ: Açlık kan şekeri, HDL: Yüksek yoğunluklu lipoprotein, LDL: Düşük yoğunluklu lipoprotein, VLDL: Çok Düşük Yoğunluklu Lipoproteinler 
çalışmalarında, ED grubundaki hastalarda koagülasyon aktivatörü olan plazma D-dimer düzeylerinin yüksek olduğunu bildirmişlerdir. Esansiyel hipertansiyonlu 178 hasta ve 48 sağlıklı gönüllünün karşılaştırıldığı ve endotelyal disfonsksiyon göstergesi olarak von Willebrand faktörünün (vWf) değerlendirildiği bir diğer çalışmada da plazma D-dimer düzeyleri hipertansiyon grubunda yüksek bulunmuştur. Ayrıca yine aynı çalışmada vWf düzeyleri ile plazma D-dimer düzeyleri arasında istatistiksel olarak güçlü bir korelasyon olduğu bildirilmiştir. ${ }^{[2]}$ Bunlara ek olarak koagülasyon sistemi aktivasyonunun ve fibrinolizin malignite ile ilişkili olabileceği öne sürülmüş fakat altta yatan patoloji henüz tam olarak aydınlatılmamıştır. LİPİD çalışması sonuçlarına göre yükselmiş plazma D-dimer düzeyleri uzun dönem arteryal ve venöz olaylar, KVH'ların gelişimi için bağımsız bir risk faktörü olarak saptanmıştır. Aynı zamanda kanser insidansı ve mortalitesi için bağımsız bir faktör olduğu yazarlar tarafından bildirilmiştir. ${ }^{[9]} \mathrm{KVH}$ ve endotelyal disfonksiyonla doğrudan ilişkisi olan ED'de plazma D-dimer düzeylerinin henüz araştırılmamış olmasını ilginç buluyoruz. Çalışma sonuçlarımızda gruplar arasında istatistiksel anlam farkı saptanmamıs olsa da, ED grubunun plazma D-dimer düzeylerinin yüksekliği dikkat çekicidir. Çalışmamızın ilk sonuçları olarak yayınladığımız bu makalede örneklem sayımızın küçük olmasının bu sonucu doğurabileceğini düşünüyoruz.

VKİ ile ED arasındaki ilişki, üroloji literatüründe çok yer bulan konulardan biridir. Kratzık ve ark. ${ }^{[13]}$, yaş, VKİ ve serum testesteron düzeylerinin $\mathrm{ED}$ ile ilişkisini araştırdıkları çalışmalarında VKİ'de $1 \mathrm{~kg} / \mathrm{m}^{2}$ lik artışın yaştan bağımsız olarak IIEF-5'i, 0,141 oranında düşürdüğünü bildirmişlerdir. 22086 katılımcıyla 14 yıllık takip sonuçlarını bildiren bir diğer çalışmada obezite ve sigara kullanımı artmış ED sıklığı ile ilişkili olarak bulunmuşken, düzenli fiziksel aktivitenin ED riskini azalttığı vurgulanmıştır. ${ }^{[14]}$ Ayrıca artmış VKİ düzeylerinin androjen metabolizması üzerine etkisi ile birlikte serum testosteron düzeylerinde azalmaya neden olduğu bilinmektedir. ${ }^{[15]}$ Bizim çalışmamızda da ED grubunun VKİ düzeyleri kontrol grubundan yüksek bulunmuştur. Çalışma sonuçlarımızın mevcut literatürü destekler nitelikte olduğu söylenebilir.

Kolesterol, hücre zarı akışkanlığının önemli bir düzenleyicisidir ve steroid hormonlarının öncüsüdür. Anormal kan lipidleri endotel disfonksiyonu için önemli bir risk faktörüdür ve endotelyal disfonksiyon ile ilgili hastalıklara neden olabilir. ${ }^{[16]}$ LDL-K düzeyindeki artışın ateroskleroz oluşumunu teşvik ederek endotelyal disfonskiyonda artışa neden olduğu bilinse de LDL-K partikülleri, kolesterolü steroidojenik dokulara taşımak için önemli bir dağıtım aracı işlevi gördüğü de bilinmektedir. ${ }^{[17]} \mathrm{Bu}$ nedenle düşük LDL-K seviyelerinin androjen seviyesinde azalmaya neden olabileceği düşünülebilir. Literatürde LDL-K düzeyleri ve serum testosteron düzeyleri arasındaki ilişki ile ilgili birbirine karşıt sonuçlar içeren yazılar mevcuttur. ${ }^{[17,18]}$ Roumeguere ve ark. ${ }^{[19]}$, hiperlipidemi ile ED arasındaki ilişkiyi inceledikleri çalışmalarında yüksek yoğunluklu lipoprotein kolesterol (HDL-K) ve total kolesterol/HDL-K düzeylerinin ED prediktörleri olduğunu bildirmişlerdir. Bu çalışmada ED grubundaki hastaların \%13,5'inde HDL-K düzeyleri <35 ng/dL olarak ölçülürken, kontrol kolunda katılımcıların $\% 5$ 'inde HDL-K düzeyleri <35 ng/dL olarak gözlenmiştir. Yazarlar belirtilen yazıda gruplar arasında LDL-K düzeyinde anlamlı farklılık gözlememişlerdir. Arteryojenik ED hastaları ile venöz yetmezliğe bağlı ED hastalarının karşılaştırıldığı bir diğer çalışmada, arteryojenik ED hastalarında serum LDL-K düzeylerinin vaskülojenik ED grubuna göre yüksek ve HDL-K düzeylerinin düşük olduğu bildirilmiştir. ${ }^{[20]}$ Bizim çalışma popülasyonumuzda da LDL-K düzeyleri $\mathrm{ED}$ grubunda kontrol grubuna yüksek gözlenmiş olsa da LDL-K, ED ve testosteron yetmezliği arasındaki ilişki hala açıklamaya değer sorular barındırmaktadır.

Çalışmamızın bazı kısıtlılıkları bulunmaktadır. Örneklem hacminin küçüklüğü çalışmanın temel kısıtlılığını oluşturmaktadır. İkinci kısıtlılık olarak, erektil fonksiyonların değerlendirildiği bir çalışmada katılımcıların eşlerinin seksüel yakınma veya tatminlerinin değerlendirilmemiş olması sayılabilir. Son olarak hastaların depresyon ve anksiyete ölçümlerinin kayıt altına alınmamış olması bir diğer kısıtlllıktır. Ürolojik literatürde ana amacı plazma D-dimer düzeyi ile erektil fonksiyonlar arasındaki ilişkiyi sorgulamak olan ilk çalışma olması çalışmamızın güçlü yanını oluşturmaktadır.

Sonuç olarak ED şikâyeti ile başvuran erkeklerde plazma D-dimer ortanca değerleri, ED'si olmayan hastalara göre daha yüksek izlense de gruplar arasında istatistiksel anlamlı bir fark saptanmamıştır. Yüksek plazma D-dimer düzeylerinin KAH'larda uzun dönem arteryal ve venöz olayların prediktörü olduğu gösterilmiştir. Vasküler ED’nin koroner hastalıkların gelişiminde risk faktörlerinden biri olduğu bilinmektedir. Çalışmamızın ilk sonuçlarında plazma D-dimer düzeyi ile $\mathrm{ED}$ arasında anlamlı ilişki olmasa da geniş örneklem gruplu ileri çalışmaların yapılmasının bu alanda gerekli olduğunu düşünmekteyiz. 


\section{Etik Kurul Onayı}

Çalışmanın tüm aşamalarında Helsinki Bildirgesi ilkeleri takip edildi. Tüm hastalar gelecekte çalışmada kullanılmak üzere verilerinin kullanımına izin verdiğini belirten bilgilendirilmiş gönüllü onamı imzalatıldı. Çalışma için yerel etik kurul onayı alındı. (onay tarihi ve sayısı: 01.04.2019 HNEAH-KAEK 2019/13).

\section{Hakem Değerlendirmesi}

Dış bağımsız.

\section{Çıkar Çatışması}

Yazarlar çıkar ilişkisi olmadığını beyan etmişlerdir.

\section{Finansal Destek}

Herhangi bir mali destek alınmamıştır.

\section{Ethics Committee Approval}

The Helsinki Declaration principles were followed at all stages of the study. Informed consent was obtained from all patients stating that they consented to the use of their data for future evaluations in the study. Local ethics committee approval was obtained for the study. (date and number of approval: 01.04.2019 HNEAH-KAEK 2019/13).

\section{Peer-review}

Externally peer-reviewed.

\section{Conflict of Interest}

No conflict of interest was declared by the authors.

Financial Disclosure

No financial support has been received.

\section{KAYNAKLAR}

1. NIH Consensus Conference. Impotence. NIH Consensus Development Panel on Impotence. JAMA 1993;270:83-90. [CrossRef]

2. Çayan S, Kendirci M, Yaman Ö, Aşçı R, Orhan İ, Usta MF, et al. Prevalence of erectile dysfunction in men over 40 years of age in Turkey: Results from the Turkish Society of Andrology Male Sexual Health Study Group. Turk J Urol 2017;43:122-9. [CrossRef]

3. Vlachopoulos C, Ioakeimidis N, Terentes-Printzios D, Stefanadis C. The triad: erectile dysfunction-endothelial dysfunctioncardiovascular disease. Curr Pharm Des 2008;14:3700-14. [CrossRef]

4. Jackson G, Boon N, Eardley I, Kirby M, Dean J, Hackett G, et al. Erectile dysfunction and coronary artery disease prediction: Evidence-based guidance and consensus. Int $\mathrm{J}$ Clin Pract 2010;64:848-57. [CrossRef]

5. Blumentals W, Gomez-Caminero A, Joo S, Vannappagari V. Should erectile dysfunction be considered as a marker for acute myocardial infarction? Results from a retrospective cohort study. Int J Impot Res 2004;16:350-3. [CrossRef]

6. Karabay E, Karsiyakali N, Cinier G, Zeren G, Duvar S, Simsek B, et al. Change in Frequency and Predictors of Erectile Dysfunction With Changes in the International Index of Erectile FunctionErectile Function Domain Score in Patients With ST-Elevation Myocardial Infarction: A Prospective, Longitudinal Study. J Sex Med 2020;17:1101-8. [CrossRef]

7. Willeit P, Thompson A, Aspelund T, Rumley A, Eiriksdottir G, Lowe $\mathrm{G}$, et al. Hemostatic factors and risk of coronary heart disease in general populations: new prospective study and updated metaanalyses. PloS One 2013;8:e55175. [CrossRef]
8. Heinrich J, Schulte H, Schönfeld R, Köhler E, Assmann G. Association of variables of coagulation, fibrinolysis and acutephase with atherosclerosis in coronary and peripheral arteries and those arteries supplying the brain. Thrombosis Haemostasis 1995;73:374-9. [CrossRef]

9. Simes J, Robledo KP, White HD, Espinoza D, Stewart RA, Sullivan DR, et al. D-Dimer Predicts Long-Term Cause-Specific Mortality, Cardiovascular Events, and Cancer in Patients With Stable Coronary Heart Disease: LIPID Study. Circulation 2018;138:712-23. [CrossRef]

10. Salonia A, Bettocchi C, Carvalho J, Corona G, Jones T, Kadioglu A, et al. EAU Guidelines on Sexual and Reproductive Health. https://uroweb.org/guideline/sexual-and-reproductive-health/

11. De Angelis L, Marfella M, Siniscalchi M, Marino L, Nappo F, Giugliano F, et al. Erectile and endothelial dysfunction in type II diabetes: a possible link. Diabetologia 2001;44:1155-60. [CrossRef]

12. Lip GYH, Blann AD, Jones AF, Lip PL, Beevers DG. Relation of endothelium, thrombogenesis, and hemorheology in systemic hypertension to ethnicity and left ventricular hypertrophy. Am J Cardiol 1997;80:1566-71. [CrossRef]

13. Kratzik CW, Schatzl G, Lunglmayr G, Rücklinger E, Huber J. The impact of age, body mass index and testosterone on erectile dysfunction. J Urol 2005;174:240-3. [CrossRef]

14. Bacon CG, Mittleman MA, Kawachi I, Giovannucci E, Glasser DB, Rimm EB. A prospective study of risk factors for erectile dysfunction. J Urol 2006;176:217-21. [CrossRef]

15. Corona G, Vignozzi L, Sforza A, Mannucci E, Maggi M. Obesity and late-onset hypogonadism. Mol Cell Endocrinol 2015;418:120-33. [CrossRef]

16. Ghosh A, Gao L, Thakur A, Siu PM, Lai CWK. Role of free fatty acids in endothelial dysfunction. J Biomed Sci 2017;24:50. [CrossRef]

17. Chen C, Zhai H, Huang G, Cheng J, Xia F, Zhao L, et al. Is lower low-density lipoprotein cholesterol associated with lower androgen and erectile dysfunction in men? Nutr Metab Cardiovasc Dis 2018;28:1304-10. [CrossRef]

18. Zhao J, Jiang C, Lam TH, Liu B, Cheng KK, Xu L, et al. Genetically predicted testosterone and cardiovascular risk factors in men: a Mendelian randomization analysis in the Guangzhou Biobank Cohort Study. Int J Epidemiol 2014;43:140-8. [CrossRef]

19. Roumeguère T, Wespes E, Carpentier Y, Hoffmann P, Schulman CC. Erectile dysfunction is associated with a high prevalence of hyperlipidemia and coronary heart disease risk. Eur Urol 2003;44:355-9. [CrossRef]

20. Li M, Ma Z, Zhang XL, Guo LQ, Yuan MZ. Significance of blood lipid parameters as effective markers for arteriogenic erectile dysfunction. Andrology 2020;8:1086-94. [CrossRef] 